TITLE:

\title{
Preparation of micro/nanocellular polypropylene foam with crystal nucleating agents
}

\section{AUTHOR(S):}

Miyamoto, Ryoma; Yasuhara, Shunya; Shikuma, Haruo; Ohshima, Masahiro

\section{CITATION:}

Miyamoto, Ryoma ...[et al]. Preparation of micro/nanocellular polypropylene foam with crystal nucleating agents. Polymer Engineering \& Science 2013, 54(9): 2075-2085

\section{ISSUE DATE:}

2013-09-19

URL:

http://hdl.handle.net/2433/200219

\section{RIGHT:}

This is the peer reviewed version of the following article: Miyamoto, R., Yasuhara, S., Shikuma, H. and Ohshima, M. (2014), Preparation of micro/nanocellular polypropylene foam with crystal nucleating agents. Polym Eng Sci, 54 :

2075-2085, which has been published in final form at http://dx.doi.org/10.1002/pen.23758. This article may be used for non-commercial purposes in accordance with Wiley Terms and Conditions for Self-Archiving.; This is not the published version. Please cite only the published version.; この論文は出版社版でありません。引用の際には出版社版をご確認じ 利用ください。 


\title{
PREPARATION OF MICRO/NANOCELLULAR POLYPROPYLENE FOAM WITH CRYSTAL NUCLEATING AGENTS
}

\author{
Ryoma Miyamoto, Shunya Yasuhara, Haruo Shikuma and Masahiro Ohshima* \\ Department of Chemical Engineering, Kyoto University, Kyoto 615-8510 \\ Correspondence to Masahiro Ohshima
}

\begin{abstract}
Open-cell, porous microcellular foams with nanofibrillated structures were prepared from high tacticity isotactic polypropylene (i-PP) with a crystal nucleating and gelling agent. 1,3:2,4 bis-O-(4-methylbenzylidene)D-sorbitol gelling agent (Gel-all MD) was used as the crystal nucleating and gelling agent, which enhanced the crystallization and gelation of i-PP with a three-dimensional network of highly connected nanofibrils. The core-back foam injection molding technique was employed to foam the i-PP with nitrogen $\left(\mathrm{N}_{2}\right)$ at a high expansion ratio, where the crystal nucleating agent induced bubble nucleation and bubble growth in the inter-lamella region and opened the cell walls with a nanoscale-fibrillated structure. The effects of the nucleating agent on the open cell content (OCC), density and crystallinity were thoroughly investigated. We prepared open-cell micro/nanocellular foams with an average cell size of microscale voids of less than $5 \mu \mathrm{m}$. Nanometer-scale fibrillated structures were formed on the cell wall of the microscale void, the expansion ratio was five-fold and the open-cell content was over $90 \%$.
\end{abstract}

Keywords: Open pore, Microcellular Foam, Foam Injection Molding, Core-back Molding, Polypropylene Foam

\section{Introduction}

Open-cell foams have specific properties, such as a high permeability, the ability to perform selective osmosis and excellent sound adsorption and dampening ${ }^{1}$. Because of these properties, open-cell foams have been used for many industrial applications, including acoustic insulators, filters, battery electrode supports, separation membranes, battery separators, tissue attachments and growth supports. The most common commercially available open-cell polymeric foams are made of polyurethane or melamine. There is still very 
little thermoplastic open-cell foams available, even though several cell-opening strategies have already been proposed for thermoplastic polymers, for example, creating high temperature differences between the surface and core of an extrudate ${ }^{2}$, using mixed blowing agents ${ }^{3,4}$ to induce secondary nucleation and change the cell densities, using interpolymer blending ${ }^{5}$ and blending two polymers with different crystallization temperatures ${ }^{6,7}$. Lee and Park et al ${ }^{6,7}$ prepared open-cell foam from polyethylene (PE) and polypropylene (PP) blends by extrusion. They proposed two strategies for opening the cell-wall of the thermoplastic polymer foams: i) The first strategy is to prepare polymer blends so that their dispersed domains can be composed of a low- $T_{c}$ (soft) polymer and the matrix can be composed of a higher- $T_{c}$ (hard) polymer. Cell-opening is then initiated through soft domains trapped between growing adjacent cells. ii) The second strategy is to prepare polymer blends so that their dispersed domains can be composed of a higher- $\mathrm{T}_{\mathrm{c}}$ (hard) and the matrix can be composed of a lower- $\mathrm{T}_{\mathrm{c}}$ (soft) polymer. Cell-opening is initiated by the debonding between the hard domain and the soft matrix. Both strategies exploited a structural inhomogeneity in polymer blends in which the difference in crystallinity or in the crystalline temperature, $T_{c}$, was used to create the inhomogeneity in the polymer.

The relationship between the crystallinity of the polymer and the foaming behavior of the polymer has been investigated for several thermoplastic semicrystalline polymers by conducting either batch or extrusion foaming experiments. ${ }^{8-11}$ Pioneering work on the thermoplastic microcellular foaming of semicrystalline polymers was conducted by Colton et al, who set the batch foaming temperature near the melting point of the polymer to be foamed ${ }^{8}$. Doroudiani et al conducted batch foaming experiments with high-density polyethylene (HDPE), polybutylene (PB), PP and poly(ethylene terephthalate) (PET) to investigate the effects of their crystallinity and the crystalline morphology of those polymers on the cell morphology ${ }^{9,10}$. They showed that controlling the cooling rate during foaming was a key factor for preparing microcellular foams from semicrystalline polymers and that the crystallinity changed the bubble nucleation behavior and made the cell structure different. 
The early studies on the relationship between crystallinity and foamability focused on the effect of crystallinity on bubble nucleation. For example, Taki et $\mathrm{al}^{11}$ experimentally showed that growing crystals during the cooling process expels the foaming agent, typically $\mathrm{N}_{2}$ and $\mathrm{CO}_{2}$, and enhances the bubble nucleation around the crystalline boundary, while the stable crystals do not induce bubble nucleation to such an extent.

Recent studies focused on the relationship between the crystallinity and the cell morphology of the foams. In particular, some papers reported the formation of a fibrillated structure that was induced by the crystals during the foaming of semicrystalline polymers. Pilla et $\mathrm{al}^{12}$ conducted extrusion-foaming of polylactide (PLA) using talc as the nucleating agent and showed that the addition of the nucleating agent increased the crystallinity of PLA, decreased the average cell size and increased the cell density. They also reported the effect of $\mathrm{CO}_{2}$ on the crystallinity and the formation of an interesting fibrillated structure on the cell wall. Xu et $\mathrm{al}^{13}$ thoroughly investigated the batch foaming behavior of $\mathrm{PP}$ with $\mathrm{CO}_{2}$ and showed that the bubble nucleation in the crystalline phase occurred when the depressurization rate was made high enough ${ }^{13}$. In their subsequent paper $^{14}$, they reported that microfibrils were formed in the amorphous phase between crystalline lamellar spherulites by $\mathrm{CO}_{2}$ batch foaming. Bao et $\mathrm{al}^{15}$ conducted batch foaming experiments with i-PP after preparing some samples with an injection-molding machine to form a shish-kebab crystalline structure in the foamed i-PP ${ }^{15}$. They claimed the shish-kebab structure became a template for creating nanocellular foams. The cell structure of their nanocellular foams was the same nanofibrillated structure as the one Xu et al reported ${ }^{13,14}$.

Preparations of open-cell thermoplastic foams by injection molding have been limited to cases combining the particulate leaching method with foaming. Kramschuster et $\mathrm{al}^{16}$ conducted foam injection molding to prepare open-cell thermoplastic foam from polylactide (PLA) and poly vinyl alcohol (PVOH) with salt as the particulate. There are still a limited number of reports on open-cell thermoplastic foam prepared by physical foam injection molding because the conventional microcellular foam injection molding could not produce a higher expansion ratio. A high expansion ratio is needed to reduce the thickness of the cell wall and 
to enhance its cell-opening. Ishikawa et $\mathrm{al}^{17,18}$ and Stumpf et $\mathrm{al}^{19}$ investigated the core-back foam injection molding technique to foam i-PP with a high expansion ratio using either $\mathrm{N}_{2}$ or $\mathrm{CO}_{2}$ as the blowing agent. They discussed the similarities and dissimilarities of core-back foam injection molding from batch foaming and indicated the possibility of realizing thermoplastic polymer foams with a higher expansion ratio.

In this study, core-back foam injection molding was employed to prepare open-cell PP with a crystalline nucleating agent. The core-back foaming method could produce microcellular foam with a higher expansion ratio and perform fine cellular foaming in a mold cavity in a manner similar to batch foaming. The nucleating agent was used to enhance the crystallization during the injection molding cooling process. It was expected that the crystals could create a structural inhomogeneity and open the cell wall with a nanofibrillated structure.

\section{Experimental}

\subsection{Materials}

The polymer used in this study was a high-tacticity isotactic polypropylene, i-PP (F133A, Prime polymer Ltd). The properties of i-PP are summarized in the section of characterization. The crystals nucleating agent was 1,3:2,4 bis-O- (4-methylbenzylidene)-D-sorbitol gelling agent (Gel-all MD, New Japan Chemical co., Ltd), whose chemical structure is given in Figure 1. This nucleating agent is normally used for improving the transparency of PP with the reduction of the crystal size.<smiles>Cc1ccc(C2OC3COC(c4ccc(C)cc4)OC3C(C(O)CO)O2)cc1</smiles>

Figure 1 Chemical structure of the 1,3:2,4-bis-O-(4-methylbenzylidene)-D-sorbitol molecule

\subsection{Core-back foam injection molding.}

A 35 ton clamping force foam injection molding machine (J35EL III-F, Japan Steel Work, Ltd.) and a gas injection device (Trexel SCF system SII TRJ-10-A-MPD) were used for the experiments (Figure 2). Nitrogen $\left(\mathrm{N}_{2}\right)$ at 0.999 purity (Izumi Sangyo, Japan) was used as a physical foaming agent. It was pressurized 
to $24 \mathrm{MPa}$ at the gas injection device and injected into the molten polymer in the barrel of the injection molding machine at 0.2 wt.\% of polymer. Mixing the gas with molten polymer at a high temperature and pressure with a screw enhances the gas dispersion and dissolution and creates a single-phase $\mathrm{N}_{2} /$ polymer solution. The temperatures of the 7 zones of the injection molding machine were set at 190, 200, 210, 210, 210, 210 and $210{ }^{\circ} \mathrm{C}$ from the bottom of the hopper to the tip of the barrel, respectively and the mold temperature was kept at $40{ }^{\circ} \mathrm{C}$ throughout our experiments. The injection speed was $40 \mathrm{~mm} / \mathrm{s}$ and the dwelling (holding) pressure was set to $40 \mathrm{MPa}$. The molding conditions are summarized in Table $\mathbf{1 .}$

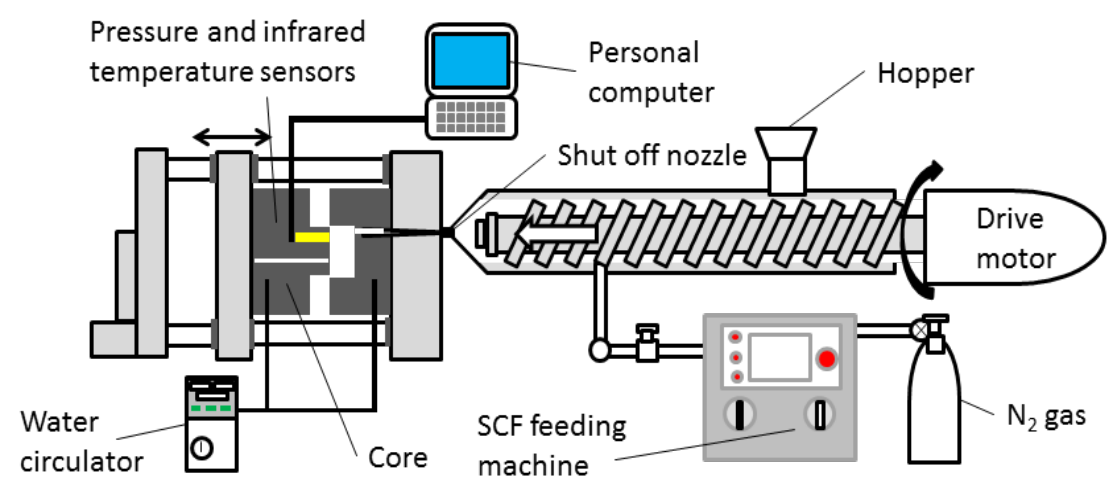

Figure 2 Schematic diagrams of the injection molding machine and a gas injection device

Table 1 Foaming conditions for investigating the effect of the core-back rate and

\begin{tabular}{|c|c|}
\multicolumn{2}{|c}{ the core-back distance } \\
\hline Barrel temperature $\left[{ }^{\circ} \mathrm{C}\right]$ & $210,210,210,210,210,200,190$ \\
\hline Mold temperature $\left[{ }^{\circ} \mathrm{C}\right]$ & 40 \\
\hline $\mathrm{N}_{2}$ weight fraction $[\mathrm{wt} . \%]$ & 0.2 \\
\hline Injection speed $[\mathrm{mm} / \mathrm{s}]$ & 40 \\
\hline Dwelling pressure $[\mathrm{MPa}]$ & 40 \\
\hline Dwelling time $[\mathrm{s}]$ & $5,5.5,6,6.5,7$ \\
\hline Core-back distance $[\mathrm{mm}]$ & $2,4,8$ \\
\hline Core-back rate $[\mathrm{mm} / \mathrm{s}]$ & $10,13,20$ \\
\hline
\end{tabular}


The polymer with $\mathrm{N}_{2}$ was injected into a core-back mold cavity to foam. The core-back mold had a box-type cavity with a gate $1.5 \mathrm{~mm}$ in diameter and a shut-off nozzle. The cavity size was $50 \mathrm{~mm}$ in width, 68 $\mathrm{mm}$ in length and $2 \mathrm{~mm}$ in initial thickness.

The core-back foam injection molding process is slightly different from the traditional structural foam injection molding process ${ }^{17,18}$ : the polymer is injected into the mold, the mold is filled up with the polymer, and a dwelling pressure is exerted on the polymer. At the end of the dwelling time, a portion of the mold is moved to quickly increase the mold cavity volume, which rapidly reduces the cavity pressure (Figure 3). The sudden pressure drop initiates the foaming, enhances the bubble nucleation and achieves the fine cell structure of polymer foams. The core-back rate, which is the rate at which the portion of the mold is opened, and the core-back distance, which is the distance moving the portion of the mold from its initial position, can be changed in the range from 0 to $40 \mathrm{~mm} / \mathrm{s}$ and from 0 to $8 \mathrm{~mm}$, respectively. By manipulating the core-back rate and distance, the expansion ratio of the cavity volume and the depression rate of the cavity pressure can be controlled. In the experiments, the core-back rate were changed at three different rates, 10,13 and $20 \mathrm{~mm} / \mathrm{s}$ and the core-back distance were set to three different distances, 2, 4 and $8 \mathrm{~mm}$.

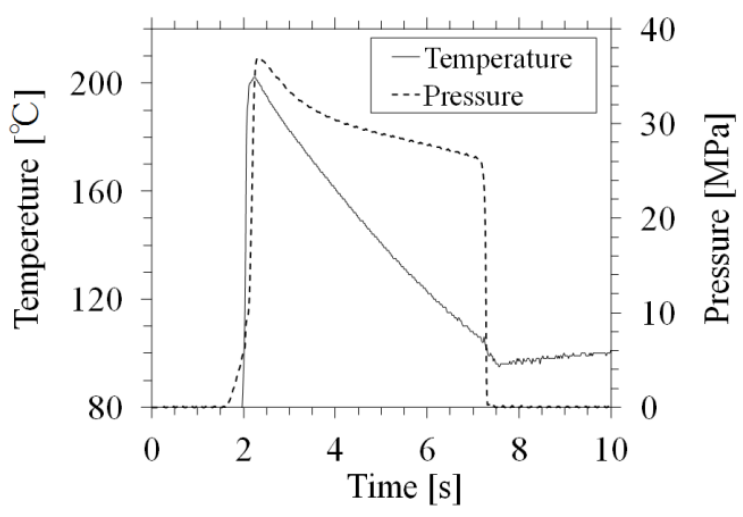

Figure 3 Pressure and temperature profiles of polymer injected into a mold cavity

A data logging system (Mold Marshaling system EPD-001, Futaba Corp.) monitored pressure and temperature in the cavity and acquired the data every 20 msec. Ejector-pin-type pressure and infrared 
temperature sensors were used for the pressure and temperature measurements. Figure 3 shows the pressure and temperature profiles of the polymer in the mold cavity, which were acquired by the data logging system. As can be observed, the temperature of the injected polymer decreased in the cavity. The polymer could be crystallized in course of the cooling process. Thus, the temperature of the polymer as well as the crystallinity and viscosity of the polymer at foaming could be controlled by the dwelling (holding) time, which is the period of time between the completion of injection and the initiation of the core-back operation.

\subsection{Characterization}

A differential scanning calorimeter (Pyris, Perkin Elmer Ltd) was used to measure the melting temperature, $\mathrm{T}_{\mathrm{m}}$, the crystallization temperature, $\mathrm{T}_{\mathrm{c}}$, and the crystallinity of foamed and non foamed PP. The measurement was conducted under $\mathrm{N}_{2}$ purge. The heating/cooling rates were set to $10{ }^{\circ} \mathrm{C} / \mathrm{min}$ and the temperature range was $40-200^{\circ} \mathrm{C}$. The crystallinity was calculated using $209 \mathrm{~J} / \mathrm{g}$ as the heat of fusion of the PP $\alpha$-form ${ }^{20}$. The properties of neat i-PP are summarized in Table 2.

Table 2 Properties of neat i-PP

\begin{tabular}{|cc|c|}
\hline \multicolumn{2}{|c|}{ tacticity [mmmm] $[\%]$} & 97 \\
\hline $\mathrm{T}_{\mathrm{m}}$ & {$\left[{ }^{\circ} \mathrm{C}\right]$} & 166.9 \\
\hline $\mathrm{T}_{\mathrm{C}}$ & {$\left[{ }^{\circ} \mathrm{C}\right]$} & 124.8 \\
\hline MFR [g/10 min] & 3.0 \\
\hline \multicolumn{2}{|c|}{ Crystallinity [\%] } & 57.5 \\
\hline
\end{tabular}

To estimate the crystallization temperature, $\mathrm{T}_{\mathrm{c}}$, in the rapid cooling process of injection molding, Flash DSC (Mettler Toledo) was used, which allows us to measure the heat curve at high heating and cooling rates in the range from 1 to $40,000{ }^{\circ} \mathrm{C} / \mathrm{s}$.

The storage modulus G' and loss modulus G” of the samples were measured by a dynamic temperature ramp tests at a cooling rate of $-2{ }^{\circ} \mathrm{C} / \mathrm{min}$ using a rheometer (Advanced Rheometric Expansion System, TA 
Instruments). The oscillation frequency was set to $1 \mathrm{~Hz}$ with $0.1 \%$ strain. The samples $25 \mathrm{~mm}$ in diameter and $2 \mathrm{~mm}$ in thickness were prepared for the rheological measurements.

A gas pycnometer (AccuPyc, Shimadzu Corp.) was used to measure the open pore content. The sample volume measured by the pycnometer excludes the open pore volume of the sample. Thus, the open cell content (OCC) was calculated by Eq. (1).

$$
O C C=\frac{V_{\mathrm{app}}-V_{\mathrm{mea}}}{V_{\mathrm{app}}} \times 100
$$

where $V_{\text {app }}$ is the apparent volume, which is geometrically measured by a caliper. $V_{\text {mea }}$ is the volume measured by the pycnometer.

Figure 4 shows a schematic view of a core-back foam injection-molded sample. A specimen was cut out after solidifying the injected sample with liquid $\mathrm{N}_{2}$ for cell morphology observation with the SEM (Tiny-SEM, Technex, Japan). The SEM observation was made from views both perpendicular and parallel to the core-back directions, as shown in Figure 4.

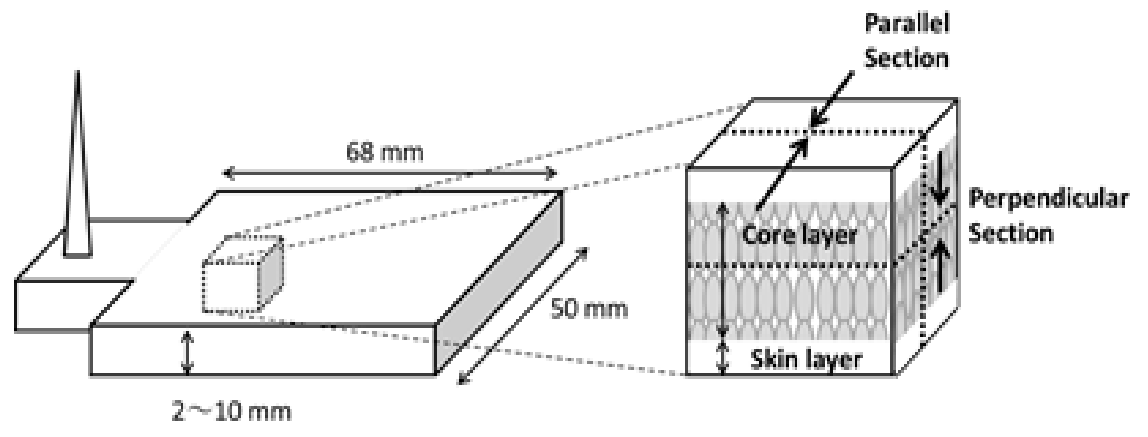

Figure 4 Schematic representation of the sample geometry showing two different sections considered for SEM observation

Figure 5 shows a digital camera and an SEM image of a cross section of a foamed sample. For the digital camera observation, the cut face was colored with ink to show the fine structure of the cell morphology. The SEM image shows that the foamed sample had a skin and core layer. In the skin layer, no bubbles were observed and the fine cellular structure was observed in the core layer. 
(a)

(c)

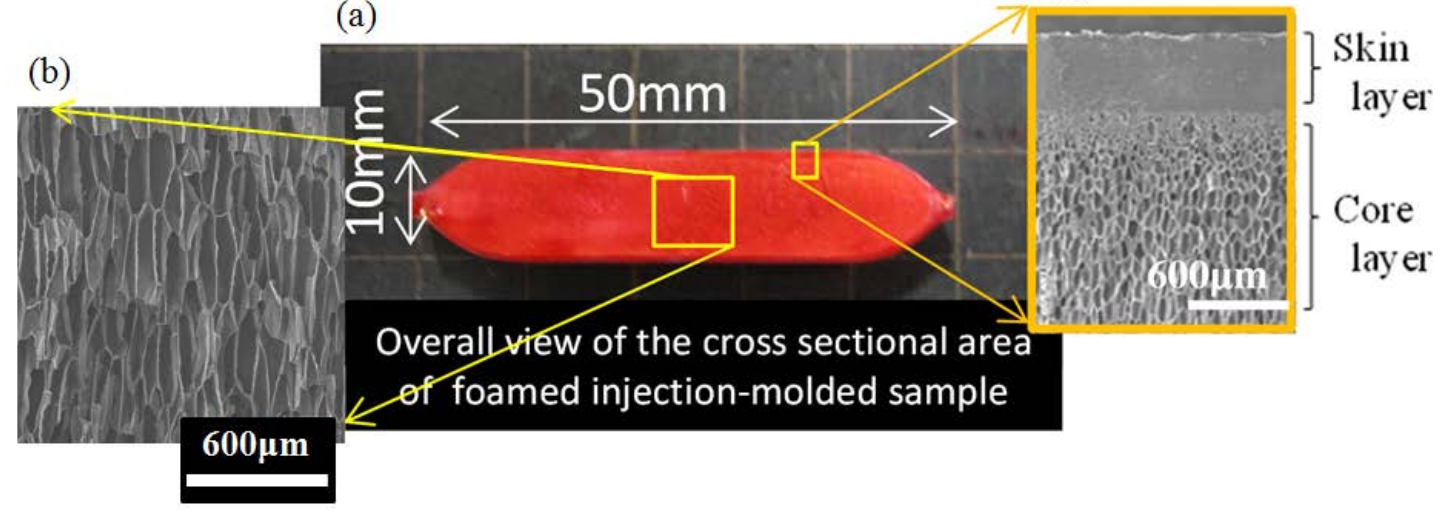

Figure 5 (a)Digital camera and (b), (c)SEM images of a cross section of the foamed sample (area was dyed with red ink for the digital camera image)
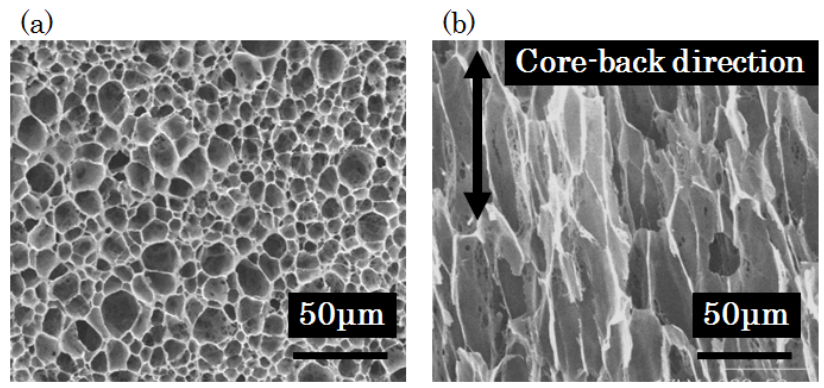

Figure 6 SEM images of the cross section of the foamed sample at the core layer (Core-back condition: core-back rate $=8 \mathrm{~mm} / 0.4 \mathrm{~s}$, MD 0.5\%, Dwelling time $=6 \mathrm{~s}$ ) (a) perpendicular and (b) parallel to the core-back direction.

Figures 6(a) and (b) show the SEM images of the cross-sectional areas of a foamed sample cut out (a) at a face perpendicular to the core-back direction and (b) parallel to the core-back direction. The sample was prepared by moving a mold part from $2 \mathrm{~mm}$ to $10 \mathrm{~mm}$ in the core-back direction. Therefore, it is clearly seen that the cells were elongated in the core-back direction and shaped to be elliptical (Fig. 6(a)). In contrast, the cell morphology observed from the view perpendicular to the core-back direction seems to be spherical (Fig. 6(a)). In the following discussion, the cell diameter, $D_{\mathrm{b}}$, was calculated from the SEM images taken in a direction perpendicular to the core-back direction with the assumption that the cell shape was spherical. Then, the degree of elongation in the core-back distance was calculated by measuring the aspect ratio of the cell from 
the SEM images. The aspect ratio was defined by the ratio of cell size, $D_{\mathrm{b}}$, to the average length, $L$, measured from the SEM images taken in the direction parallel to the core-back direction.

The cell density, $N_{\mathrm{d}}$, was often calculated from the SEM images using the following equation ${ }^{21}$ :

$$
N_{\mathrm{d}}=\left(\frac{N}{A}\right)^{\frac{3}{2}}
$$

where $N$ is the number of cells observed in the SEM image taken from the direction perpendicular to the core-back direction and $A$ is the area of the image.

However, because the cells were elongated in the core-back direction and their shape became prolate spheroidal, the calculation scheme, Eq.(2) of the cell density, $\mathrm{N}_{\mathrm{d}}$, has to be modified for this study. The cell density of the prolate spheroidal cell, $N_{\mathrm{d}}$ ellipsoid, was calculated by modifying Eq.(2) with the void fraction, $\phi_{\mathrm{v}}$. 22

$$
N_{d, \text { ellipsoid }}=\frac{6 \phi_{\mathrm{v}}}{\pi L D_{b}{ }^{2}}=\frac{6}{\pi L D_{b}{ }^{2}}\left(1-\frac{\rho_{\text {foam }}}{\rho_{\text {polymer }}}\right)
$$

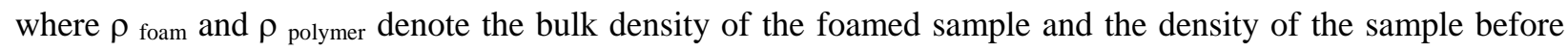
foaming, respectively.

\section{Results and Discussion}

\subsection{Formation of open-cell foams}

Figure 7 shows an SEM image of the i-PP foamed with 0.5 wt.\% nucleating agent, Gel-all MD. The foam injection molding was conducted with $8 \mathrm{~mm}$ of core-back distance, $6 \mathrm{~s}$ of dwelling time and a $20 \mathrm{~mm} / \mathrm{s}$ core-back rate. The sample was prepared by shifting the mold part from $2 \mathrm{~mm}$ to $10 \mathrm{~mm}$; thus, the expansion ratio of the foamed sample increased fivefold. The image was taken perpendicularly to the core-back direction. As can be observed, micrometer-scale cells with an average cell diameter of approximately $5 \mu \mathrm{m}$ were observed. At the same time, nanometer-scale fibrils were observed, as shown in the higher-magnification SEM image in the bottom right corner in Fig. 7. The pores were formed by nanofibrils. 


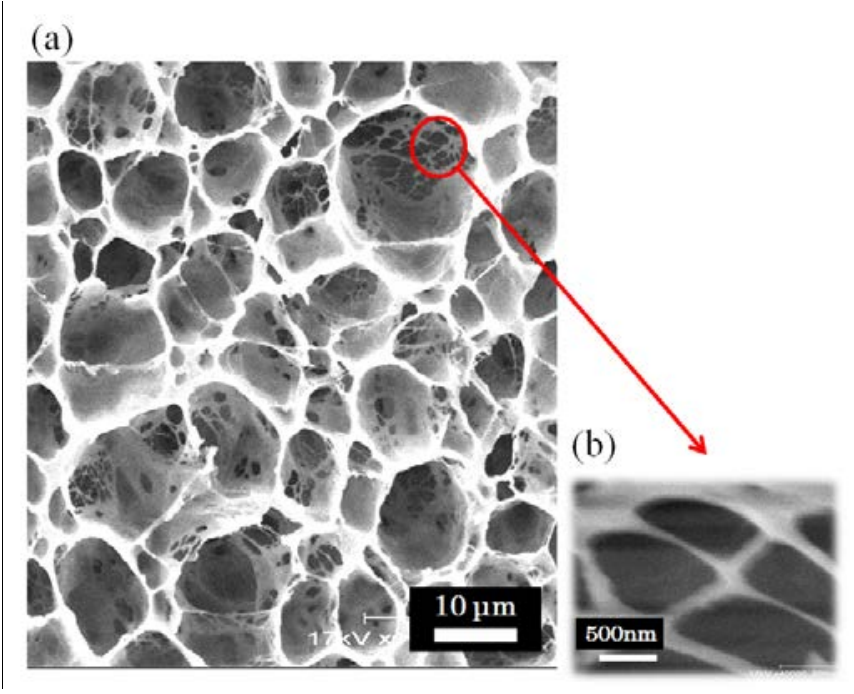

Figures 7 (a) SEM image of an injection-foamed sample (perpendicular view to the core-back direction). (b) a higher magnification SEM featuring the cell wall.

\subsection{Effect of the crystal nucleating agent on the cell morphology}

Figures 8 a-f show SEM images of the samples with and without the crystal nucleating agent (MD). The left column (Figs. 8-a, c, e) shows the images of the sample foamed without nucleating agent at different core-back distances. The right column (Figs. 8-b, d, f) shows the images of the sample foamed with 0.5 wt.\% nucleating agent by setting different core-back distances. It is observed that, by adding the crystal nucleating and gelling agent, the cell size was decreased and the cell density was increased.

The highest expansion (fivefold) was achieved for these foams by setting the core-back distance at $8 \mathrm{~mm}$ and expanding the sample thickness from 2 to $10 \mathrm{~mm}$ (Figs. 8 e and f). Figures $8 \mathrm{~g}$, and h clearly show that, by adding the Gel-all MD nucleating agent, the cell walls were opened and fibrillated with nanofibers in high expansion foams 

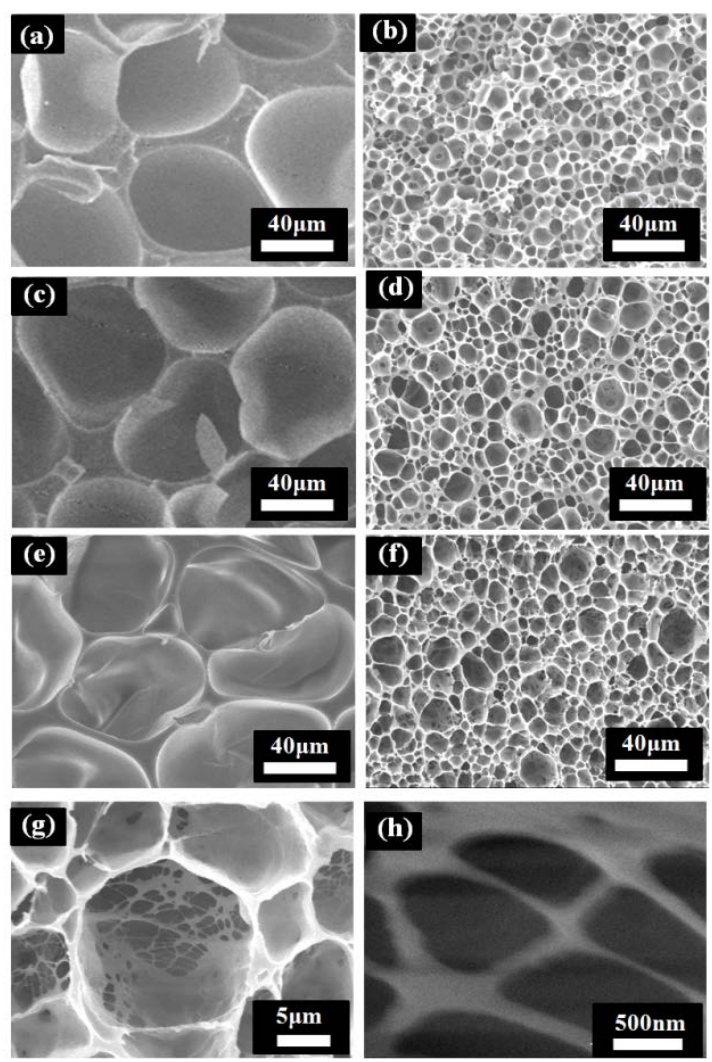

Figure 8 -SEM images of the cross-sectional areas of the core layer of samples foamed with and without MD. All images were taken perpendicularly to the core-back direction. (a) Core-back conditions: $2 \mathrm{~mm} / 0.1 \mathrm{~s}, \mathrm{MD}$ 0\%; (b) $2 \mathrm{~mm} / 0.1 \mathrm{~s}, \mathrm{MD} 0.5 \%$; (c) $4 \mathrm{~mm} / 0.2 \mathrm{~s}$, MD 0\%; (d) $4 \mathrm{~mm} / 0.2 \mathrm{~s}, \mathrm{MD} 0.5 \%$; (e) 8 mm/0.4 s, MD 0\%; (f) $8 \mathrm{~mm} / 0.4 \mathrm{~s}$, MD 0.5\%; (g) higher magnification of the part (f); and (h) further high magnification of part (g). The dwelling time was set to $6 \mathrm{~s}$ for all samples.

Figures 9-a and $\mathbf{b}$ show the cell diameter, $D_{\mathrm{b}}$, and on the cell density, $N_{\mathrm{d}}$ ellipsoid, of the samples foamed at different expansion ratios (core-back distances). The core-back rate was set to $20 \mathrm{~mm} / \mathrm{s}$ for all samples. The cell size was observed perpendicularly to the core-back direction. As can be observed, $D_{\mathrm{b}}$ did not drastically change as a function of the core-back distance when the crystal nucleating agent (Gel-all MD) was used. In contrast, the cell was elongated in the core-back direction in response to the core-back distance. Figure $\mathbf{1 0}$ shows the effect of the expansion ratio on the aspect ratio. It was observed that the aspect ratio is proportional to the expansion ratio. 
(a)

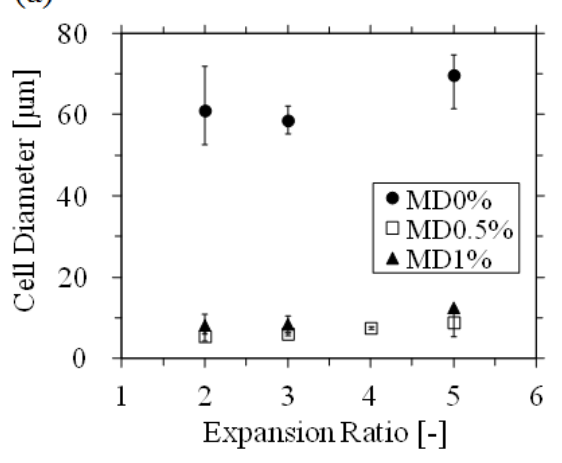

(b)

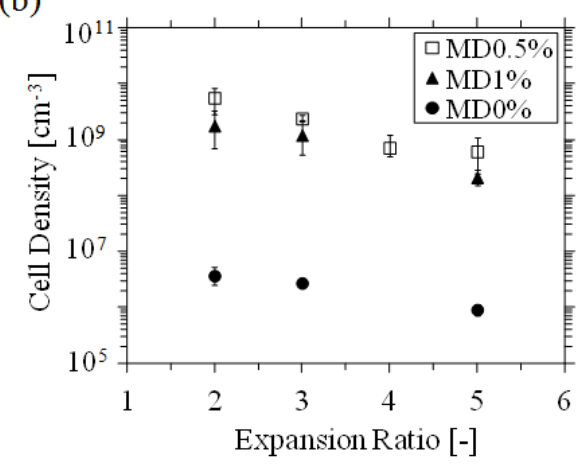

Figure 9 Foam (a) the cell diameter, $\mathrm{D}_{\mathrm{b}}$, and (b) the cell density, $N_{\mathrm{d}}$, ellipsoid, as a function of the expansion ratio. Sample obtained with a dwelling time $6 \mathrm{~s}$ and Core-back rate $20 \mathrm{~mm} / \mathrm{s}$.

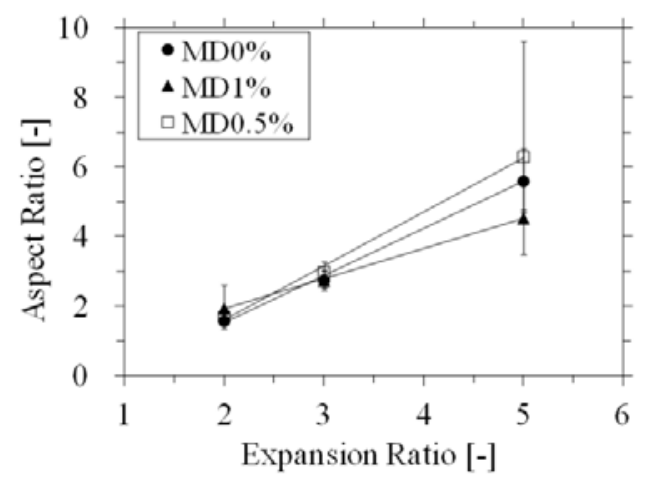

Figure 10 Cell aspect ratio of the foamed sample at the core position as a function of the expansion ratio (Foaming conditions: Dwelling time $=6 \mathrm{~s}$ and Core-back rate $=20 \mathrm{~mm} / \mathrm{s}$ ).

As can be seen in Figs. 8 and 9, the crystals nucleating agent drastically reduced the cell size and increased the cell density and the effects of crystals nucleating agent on cell size and density were dominant than the effects of the expansion ratio. It appears that the crystal nucleating agent, Gel-all MD, induced the crystallization of the i-PP and created the many tiny crystals ${ }^{23}$. Thus, it is highly possible that these small crystals provided bubble nucleation sites and enhanced the heterogeneous bubble nucleation. In addition, the nucleating agent modified the elastic property of the i-PP so that the cell growth could be suppressed and the cell size could be reduced. Figure 11 shows the storage modulus of the PP samples with and without the 
crystals nucleating agent. It was observed that the nucleating agent provoked an increase in the storage modulus G' in the temperature range from 140 to $180^{\circ} \mathrm{C}$. Kobayashi et al ${ }^{23}$ reported that Gel-all MD was able to increase the elasticity of i-PP at temperatures higher than $T_{c}$ due to gelation effects. Thus, it can be considered that in the foaming process the crystals nucleating agent could suppress bubble growth and reduce cell size with the network structure of Gel-all MD.

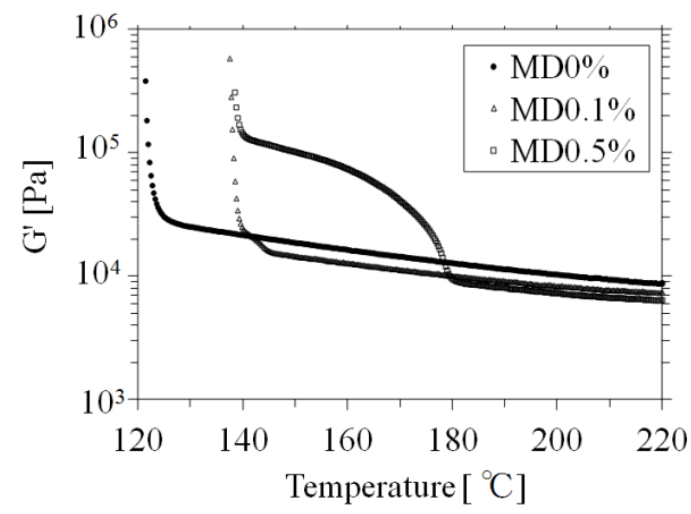

Figure 11 Storage modulus G' of i-PP, i-PP with 0.1 wt.\% Gel-all MD and i-PP with0.5 wt.\% Gel-all MD (at cooling rate $-2^{\circ} \mathrm{C} / \mathrm{min}$, frequency $1 \mathrm{~Hz}, 0.1 \%$ strain, with a parallel plate device)

The increase in the amount of crystals nucleating agent led to an increase in G'. The higher G' reduced the cell growth and suppressed the elongation of the cell in the core-back direction, as shown in Figs. 9 and 10. However, the rheological data shows that 0.1 wt.\% crystals nucleating agent could not increase in G' even though $\mathrm{T}_{\mathrm{c}}$ could be shifted to higher temperature. This indicates that the certain amount of Gel-all MD is needed to provoke the increase in storage modulus. At the same time, the cell diameter and density were not changed so much by increasing the amount of Gel-all MD from 0.5 to $1 \mathrm{wt} . \%$. It would be necessary to carry out further experiments to determine the optimal concentration of crystal nucleating agent.

\subsection{Effect of the expansion ratio and crystals nucleating agent on open cell content}


Figure 12 shows the open cell content (OCC) of the foamed samples as a function of the expansion ratio. The OCC was measured after peeling out the skin layers from the foamed samples. It was observed that the open-cell content increased with the increase in the crystal nucleating agent (Gel-all MD) and the increase in the expansion ratio. Because the thickness of the cell wall was reduced by achieving the high expansion while keeping the cell size in the micrometer scale, cell-opening was initiated more easily. In addition, the Gel-all MD could enhance crystallization and gelation and it could form a nano-fibrillated structure when the cell wall was elongated. The fibrillated structure on the cell wall kept the OCC of the PP with Gel-all MD higher than $80 \%$ in the range of expansion ratio 3 to 5 .

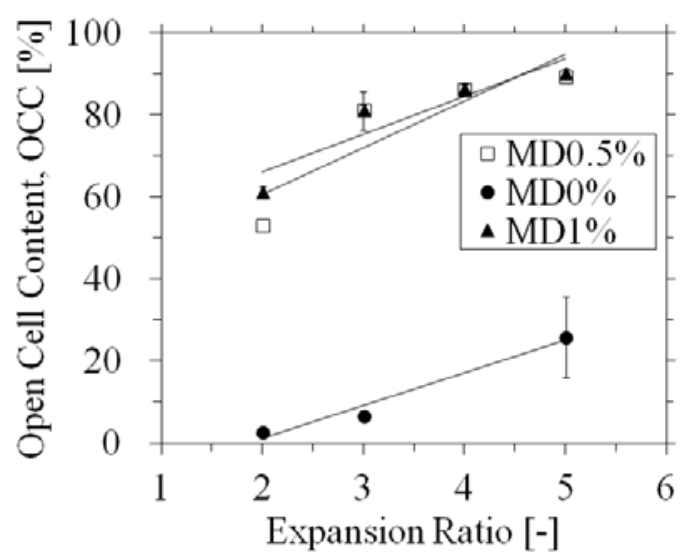

Figure 12 Open pore content of the foamed sample at the core position as a function of the expansion ratio (Foaming conditions; dwelling time $=6 \mathrm{~s}$ and Core-back rate $=20 \mathrm{~mm} / \mathrm{s}$ ).

Figure 13 shows the crystallinity of the samples obtained by injection foaming at different expansion ratios with different Gel-all MD concentrations but the same core-back rate, $20 \mathrm{~mm} / \mathrm{s}$. The samples were cut from the same position that we took the piece for SEM observation. It was observed that the crystallinity was increased not only by adding the nucleating agent but also by increasing the expansion ratio. This might indicate the occurrence of oriented or shear-induced crystallization and the correlation between crystallinity and fibrils formation on cell wall. Controlling the crystallinity in the cooling process with a nucleating agent 
and the expansion ratio would be the key factor for cell-opening with a fibrillated structure in foam injection molding with core-back operation.

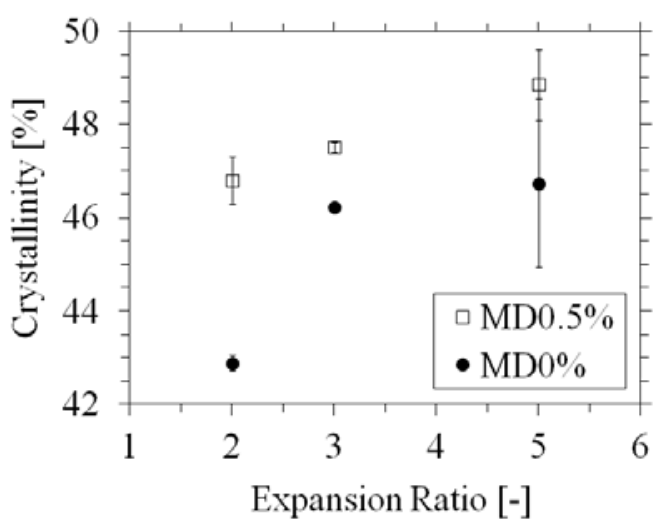

Figure 13 Crystallinity of the foamed samples as a function of the expansion ratio (Foaming conditions; dwelling time $=6 \mathrm{~s}$ and Core-back rate $=20 \mathrm{~mm} / \mathrm{s}$.)

\subsection{Effect of the core-back rate on the cell morphologies}

Figure 14 shows the effects of the core-back rate on the cell size, $\mathrm{D}_{\mathrm{b}}$, cell density, $\mathrm{N}_{\text {elliptic}}$, and open cell content (OCC).
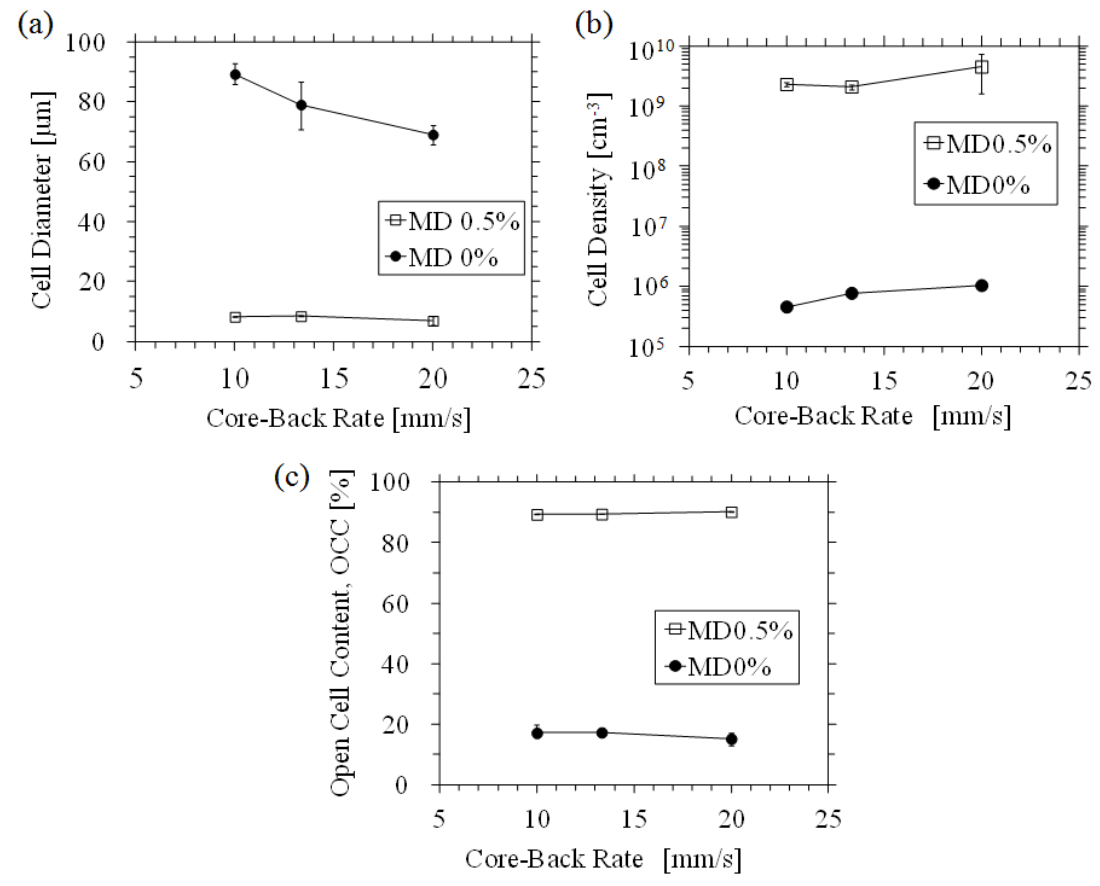
Figure 14. Effect of the core-back rate on (a) the cell diameter, (b), cell density and (c) open cell content ( Foaming conditions; dwelling time $=6 \mathrm{~s}$, expansion ratio $=8 \mathrm{~mm})$.

As can be seen in Fig. 14, by adding the crystal nucleating agent, the cell diameter, $\mathrm{D}_{\mathrm{b}}$, was drastically decreased, the cell density, $\mathrm{N}_{\text {elliptic}}$, was increased and the OCC was increased at all core-back rates. The effects of the crystals nucleating agent on the cell size and density are stronger than the effect of the core-back rate.

As the core-back rate was increased, the cell diameter was reduced, regardless of the presence of a crystal nucleating agent. When the crystal nucleation agent was added, the degree of cell size reduction with the increase of core-back rate was not as high as that of the neat i-PP but it still existed. This is the same effect the depressurization rate has on the cell size, which we have been able to observe in batch and extrusion foaming processes $2,3,17$. Based on these experimental results, it could be said that the bubble nucleation occurred at the time when the core-back operation was conducted but not at the time when the polymer was injected into the cavity of the mold.

\subsection{Effect of the dwelling time on cell morphology}

Figure 15 shows the effects of the dwelling time on the cell size, $D_{b}$, the cell density, $N_{\text {elliptic, }}$ the expansion ratio and the open cell content (OCC). Figure 16 shows SEM micrograph of the i-PP foams at different dwelling time. For the neat i-PP (MD 0\%), when the dwelling time was $5.5 \mathrm{~s}$, the foam could not maintain cellular structure but it showed a fibrillar structure as illustrated in Figure 16 a. Therefore, the cell density and the cell diameter could not be measured for the foams with the complete fibrillar structure. When the dwelling time was further shorten to 5 s, the foam of neat i-PP was blown out and neither cellular nor fibrillar structure was obtained. On the other hand, when the dwelling time was set to be longer than $6 \mathrm{~s}$, the cellular structure was obtained as illustrated in Figure 16b. 
For the i-PP with $0.5 w t . \%$ crystals nucleating agent, when the dwelling time was set to $4.75 \mathrm{~s}$, the mixture of fibrillate and cellular structures were obtained as shown in Figure 16 c, where the cell size and density were still measureable. With the increase in dwelling time, the cellular structure became dominant as illustrated in Fig. 16d. At the same time, the cell size was decreased and the cell density was increased by increasing the dwelling time. When the dwelling time was set longer than $5.5 \mathrm{~s}$, the microcellular foam with nano-fibrillated wall were obtained as shown in Figs. 6 and 7.

As the dwelling time was set to be longer, the foaming temperature was decreased and the viscoelasticity was increased. When the dwelling time was set to be too long, the viscosity of polymer in the cavity became too high to expand the polymer. Consequently, the actual expansion ratio was drastically dropped. This is the phenomena observed at the foams when the dwelling time exceeded $6.5 \mathrm{~s}$ (Fig. $15 \mathrm{~d}$ ). Here actual expansion ratio was obtained from the foam density. Furthermore, as the dwelling time was increased, the amount of the blowing agent escaping from the injected polymer before the coreback operation was increased and the blowing agent concentration in the polymer was decreased. Thus, the degree of super-saturation at foaming was decreased. As a result, with the increase in the dwelling time, the cell density was decreased and the cell size was increased. This is the phenomena observed at the neat i-PP foams when the dwelling time was set to longer than $7 \mathrm{~s}$.

The second horizontal axis in Fig. 15 indicates the temperature of the polymer at the time the coreback operation was conducted, i.e., the dwelling time was ended. As can be seen in Figs 15 and 16, when the dwelling time was set to $5.5 \mathrm{~s}$, the polymer temperature was about $111{ }^{\circ} \mathrm{C}$. Figure 17 shows the non-isothermal crystallization behaviors of both neat i-PP and i-PP with Gel-all MD. The measurement was conducted by the Flash DSC at the high cooling rate, $19{ }^{\circ} \mathrm{C} / \mathrm{s}$, which is about the same cooling rate of the polymer in the cavity of the injection molding machine used in this study. As the measured heat curves indicated, $111{ }^{\circ} \mathrm{C}$ corresponds to the temperature at which the crystallization of i-PP startes in the rapid cooling process. It was also indicated that the crystallization rate was increased by the crystals nucleating agent even in the rapid cooling process $\left(-19^{\circ} \mathrm{C} / \mathrm{s}\right)$. Comparing these DSC measurements (Fig. 17) with the cell 
morphologies obtained at different dwelling times (Figs. 15 and 16), it can be said that the transition of fibrillate structure to cellular structure was strongly related to the crystallization of the polymer.

As shown in Fig. 15, the dwelling time, $5 \mathrm{~s}$, corresponds to the foaming temperature, $118^{\circ} \mathrm{C}$, which is slightly higher than $\mathrm{T}_{\mathrm{c}}$ in the rapid cooling process. For the neat i-PP, the cellular structure could not be formed at the dwelling time 5 s. On the other hand, for the i-PP with Gel-all MD, the cellar structure could be maintained together with fibrillate structure as shown in Fig. 16c. This difference might be caused by the three dimensional network structure of Gel all MD.

(a) Temperature at Core-Back timing $\left[{ }^{\circ} \mathrm{C}\right]$

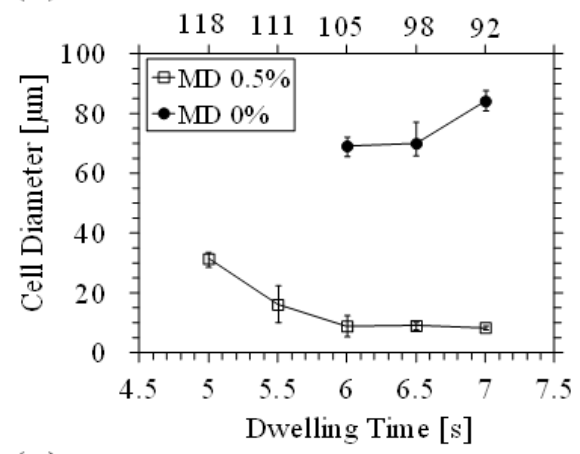

(b) Temperature at Core-Back timing $\left[{ }^{\circ} \mathrm{C}\right]$
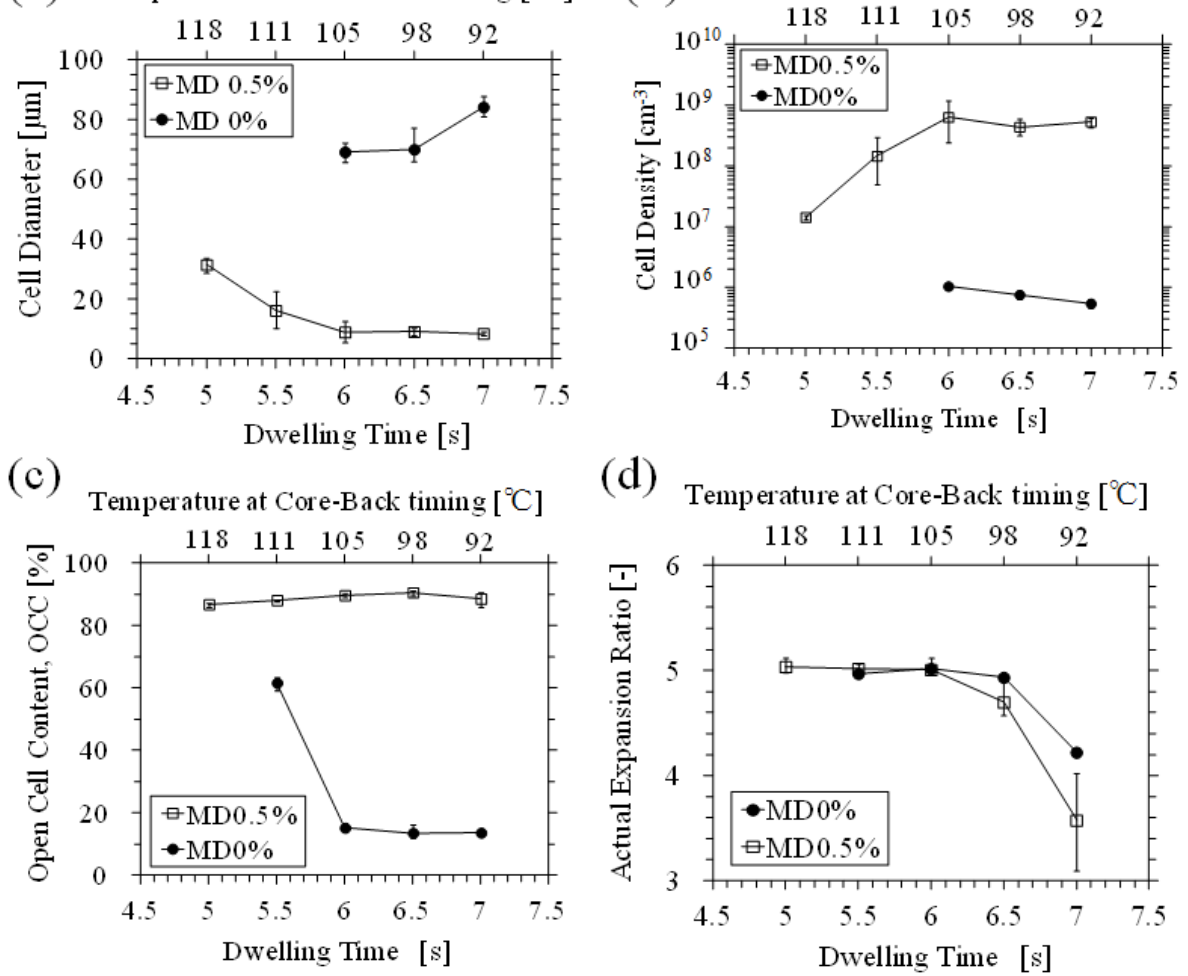

(d)

Temperature at Core-Back timing $\left[{ }^{\circ} \mathrm{C}\right]$

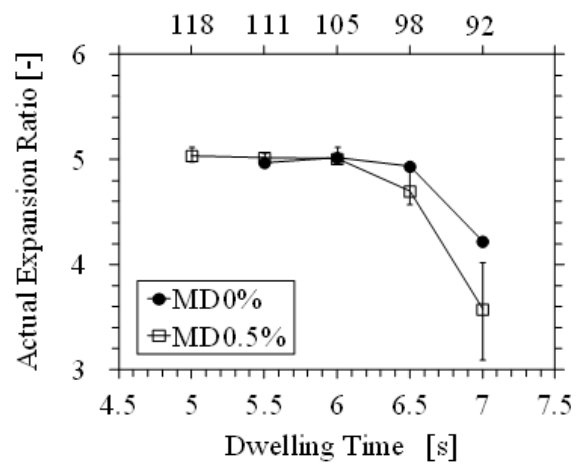

Figure 15 Effect of the dwelling time on (a) the cell diameter, (b) cell density and (c) open cell content, (d) actual expansion ratio ( Foaming conditions; dwelling time $=6 \mathrm{~s}$, core-back distance $=8 \mathrm{~mm}$ ). 

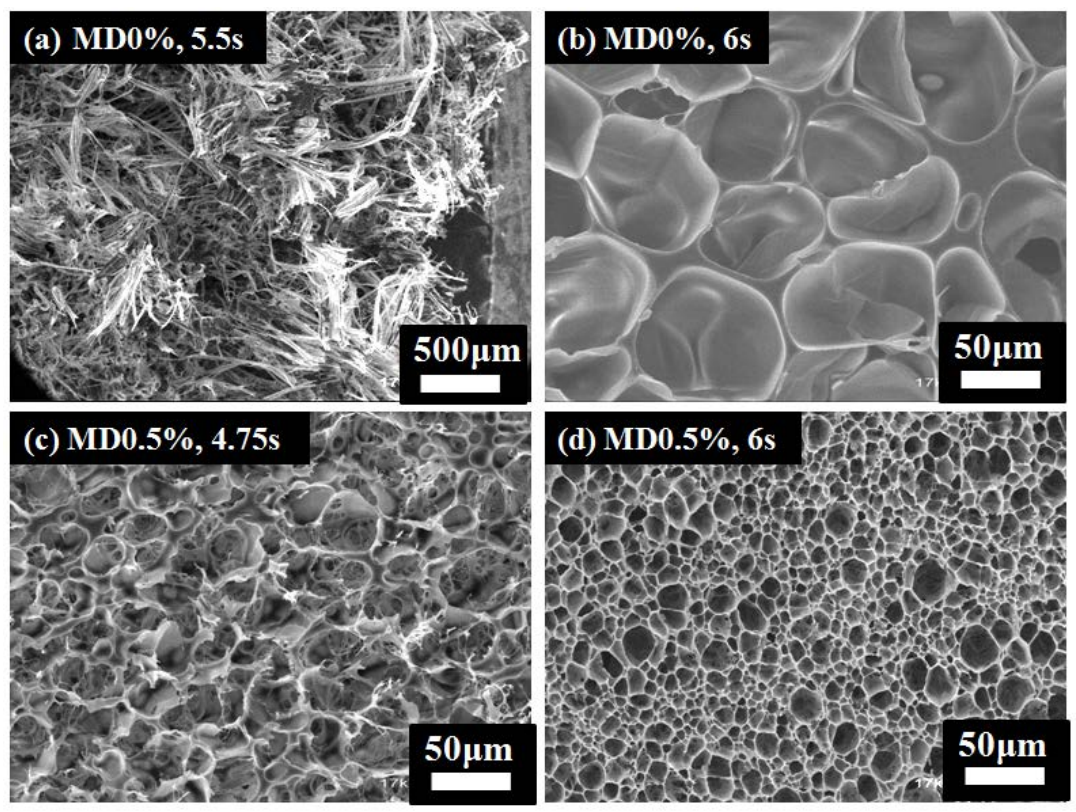

Figure 16 SEM micrographs of the foams of i-PP (c), (d) with( MD0.5\%) and (a), (b) without, the effect of dwelling time on the cell morphology ( Foaming conditions; core-back distance $=8 \mathrm{~mm}$, rate $=20 \mathrm{~mm} / \mathrm{s}$ )

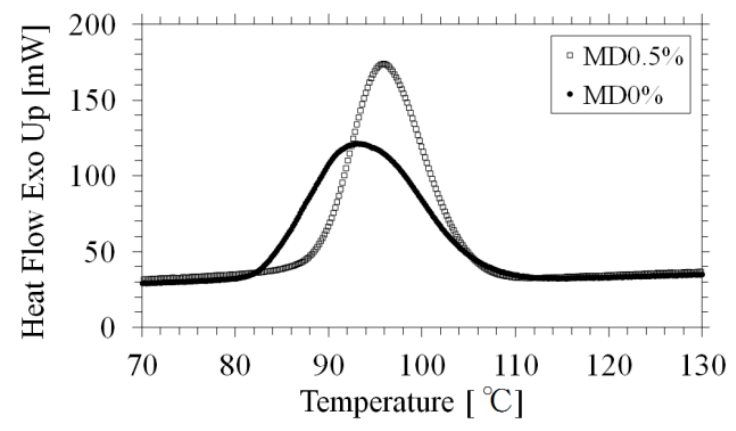

Figure 17 Heat curves of i-PP and i-PP with MD0.5\% in a rapid cooling process $\left(-19.3^{\circ} \mathrm{C} / \mathrm{s}\right)$

\section{Conclusions}

Highly open-porous microcellular polypropylene foams with nanofibrils were prepared by core-back foam injection molding. A new strategy of cell opening was proposed in this study: a structural inhomogeneity was created using the crystallization induced by a nucleating agent and stretching in the core-back direction. By adding the nucleating agent, the crystallinity was increased and the elasticity was increased. The higher elongation of the cell wall enhanced the nanoscale-fibril formation in the amorphous phase between crystalline 
lamellar spherulites. The cell walls were opened and composed of nanoscale fibrils. As a result, the open cell content increased. The high expansion ratio, i.e., 5 times as large as the initial volume with a high open cell content, higher than $90 \%$, was successfully achieved while keeping the average cell size less than $5 \mu \mathrm{m}$. The dwelling time was a key parameter for controlling the cell size and the expansion ratio.

\section{Acknowledgements}

This research was conducted for the NEDO Project to Develop Innovative Non-fluorocarbon Heat Insulation Technology.

\section{References}

1. J. McRae, H.E. Naguib and N. Atalla, J. App. Polym. Sci., 116, 1106 (2010)

2. P.C. Lee, G. Li, J. W.S. Lee, C. B. Park, J. Cell. Plast., 43, 431 (2007)

3. P.C. Lee, H. E. Naguib, C. B. Park, J. Wang, Polym. Eng. Sci., 45, 1445 (2005)

4. US. Patent 6174471 (2001), The Dow Chemical Company MI, invs: C. P. Park, B. Chaudhary, D. Imeokparia.

5. D. Kohlhoff and M. Ohshima, Macromol. Mater. Eng., 296, 770 (2011)

6. P.C. Lee, J. Wang, and C.B. Park, Ind. Eng. Chem., 45, 175. (2006)

7. C.B. Park, V. Padareva, P.C. Lee, H.E. Naguib, J. Polym. Eng., 25, 239 (2005)

8. J.S. Colton, Materials and Manufacturing Processes, 4, (2), 253 (1989)

9. S. Doroudiani, C.B Park, M.T. Kortsch, Polym. Eng. Sci., 36, (11), 2645 (1996)

10. S. Doroudiani, C.B Park, M.T. Kortsch, Polym. Eng. Sci., 38, (7), 1205 (1998)

11. K. Taki, D. Kitano, and M. Ohshima, Ind. Eng. Chem. Res., 50, 3247 (2011)

12. S. Pilla, S.G. Kim, G.K. Auer, S. Gong, and C.B. Park, Polym. Eng. Sci.,49, 8, 1653 (2009)

13. Z.M. Xu, X.L. Jiang, T. Liu, G.H. Hu, L.Zhao, Z.N. Zhu,W.K.Yuan, J. Supercritical Fluids, 41, 299 (2007) 
14. X.L. Jiang, T. Liu, Z.M. Xu, G.H. Hu,W.K.Yuan, J. Supercritical Fluids, 48, (2), 167, (2009)

15. J. B. Bao, T. Liu, L. Zhao, D Barth, G.H. Hu Ind. Eng. Chem. Res,. 50, 13387 (2011)

16. A. Kramschuster, L.S Turng J. Biomed. Mater. Res. Part B, 92, B, 366 (2010)

17. T. Ishikawa and M. Ohshima, Polym. Eng. Sci., 51, (8), 1617 (2011)

18. T. Ishikawa, K. Taki, and M. Ohshima, Polym. Eng. Sci.,52, (4), 875 (2011)

19. M. Stumpf, A. Sporrer, H.W. Schmidt, V. Alstadt, J. Cellular plastics,47, (6) 519(2011)

20. W. R. Krigbaum, I. Uematsu, J. Polym. Sci., Part A, 3, 767 (1965)

21. V. Kumar, NP. Suh, Polym. Eng. Sci., 30, No. 20, 1323 (1990)

22. R. Gosselin, D Rodrigue, Polym. Testing, 24, 1027 (2005)

23. T Kobayashi, T Hashimoto, Bull. Chem. Soc. Jpn., 78, 218 (2005) 